\title{
Managing Organizational performance of pharmaceutical SMEs in Indonesia: Examining the Role of Entrepreneurial Orientation and Organizational Learning in a Mediated Model
}

\author{
Saeed Abbas Shah ${ }^{1}$, Muzafar Hussain Shah ${ }^{2,}$, , Sheema Matloob ${ }^{3}$ and Syed Iradat Abbas ${ }^{4}$ \\ ${ }^{1}$ Business Administration, Sukkur IBA University, Pakistan \\ s.abbas@iba-suk.edu.pk \\ ${ }^{2}$ School of Economics Finance and Banking, College of Business, Universiti Utara Malaysia \\ syedmuzafar110@gmail.com \\ 3School of Management Universiti Sains Malaysia \\ sheemamatloob1100@outlook.com \\ ${ }^{4}$ Universiti Islam Antarabangsa Sultan Abdul Halim Mu'adzam Shah (UniSHAMS), Malaysia, \\ iradat002@hotmail.com. \\ Correspondence: syedmuzafar110@gmail.com
}

Received: $2^{\text {nd }}$ December 2020; Accepted: 18 ${ }^{\text {th }}$ January 2021; Published: $1^{\text {st }}$ February 2021

Abstract: The theme of the current research is to assess the link between entrepreneurial orientation, organizational learning with organizational performance using structural equation modeling. The current work was based on a quantitative approach using cross-sectional survey methodology. The study examined the effect of entrepreneurial orientation (EO) on organizational learning (OL), organizational performance (OP), and of organizational learning (OL) on organizational performance (OP). Moreover, the study also examined the mediating effect of organizational learning (OL) in the relationship between entrepreneurial orientation (EO), and organizational performance (OP). Data were collected from managers and owners of manufacturing pharmaceutical SMEs in Indonesia. A sample of $\mathbf{3 4 0}$ was selected by using the purposive sampling technique. The results support in current empirical model confirming all the direct hypothesized relationships. The study results also revealed mediation of organizational learning in the entrepreneurial orientation and organizational performance relationship. Considering the association of the factors studied in the current research, the authors imply managers, owners to develop a learning-oriented environment. The implication sections provide further details based on the results.

Keywords: Entrepreneurial Orientation; Organizational learning; organizational performance; SMEs Indonesia

Saeed Abbas Shah, Muzafar Hussain Shah, Sheema Matloob and Syed Iradat Abbas, "Organizational performance of pharmaceutical SMEs of Indonesia in light of entrepreneurial orientation: An intervening role organizational learning", Annals of Contemporary Developments in Management \& HR (ACDMHR), Print ISSN: 2632-7686, Online ISSN: 2632-7694, pp. 24-32, Vol. 1, No. 1, 1'st February 2021, Published by International Association of Educators and Researchers (IAER), DOI: 10.33166/ACDMHR.2021.01.003, Available: http://acdmhr.theiaer.org/archive/v3/v3n1/p3.html. 


\section{Introduction}

Siriattakul et al. (2019) and Hair et al. (2014) have regarded SMEs as facilitation units for employment generation, financial development and competitiveness worldwide. SMEs are accepted equally in theoretical and practical perspectives as the engine to solve unemployment problems, reduce poverty, and other socioeconomic issues. SMEs provide about $80 \%$ of employment in Southeastern Asia as economic integration to ASEAN, and it contributes about $50 \%$ to GDP, and region consists of about $96 \%$ of enterprises in the region(Rosli, Lokman, Aziz, \& Hamidi, 2015; Siriattakul, Saengchai, \& Jermsittiparsert, 2019).

As for concern to Indonesian SMEs, especially the pharmaceutical sector, which is treated as a strategic industry, the Indonesian pharmaceutical industry needs support from Indonesians. Unfortunately, pharmaceutical SMEs' performance is on the lower end. This indicates the lower organizational performance of Indonesian pharmaceutical SMEs. Furthermore, the contribution to GDP by pharmaceutical SMEs in Indonesia decreased from $0.80 \%$ in 2009 to $0.65 \%$ in 2014 . In such a situation, top management officials in the pharmaceutical sector have to focus on improving organizational performance. Keeping in view the objectives, the current study has examined the consequence of entrepreneurial orientation on organizational performance. Alongside, the current study has also tested the mediating effect of organizational learning in the relationship between entrepreneurial orientation and organizational performance to forward strong empirical results to help support the pharmaceutical SME sector, which, as per Table 1, has a significant contribution to the Indonesian economy.

Table 1. SMEs Contribution in Indonesia (Bappenas, 2018)

\begin{tabular}{lllll}
\hline Type & \multicolumn{2}{c}{ Number } & GDP & Employment \\
\cline { 2 - 5 } & Units & Share & & \\
\hline Micro & 62.106 & $98.7 \%$ & $30.06 \%$ & $89.17 \%$ \\
Small & 0.757 & $1.20 \%$ & $12.54 \%$ & $4.74 \%$ \\
Medium & 0.058 & $0.09 \%$ & $14.49 \%$ & $3.11 \%$ \\
Total & 62.922 & $99.99 \%$ & $57.08 \%$ & $97.02 \%$ \\
\hline
\end{tabular}

\section{Review of Existing Literature}

\subsection{Organizational Performance}

Organizational performance is one of the essential factors in different empirical works in the area of management. Organizational performance plays an important key role in monitoring, implementing, and developing strategic plans according to future targets (Teeratansirikool et al., 2013). According to Gavrea et al. (2011) and Mehralian et al. (2017), the growth of any organization is dependent on its performance, which can only be achieved with effective organizational progress (Gavrea et al., 2011; Mehralian et al., 2017). Organizational performance is referred as the output of a business entity as per its set goals and objectives C.-C. Lee, Lin, Yang, Tsou, \& Chang, 2013). According to Ho (2008), through organizational performance, organizations achieve targets. Similarly, organizational performance has a vital role in the growth of SMEs and, more importantly for pharmaceutical SMEs. In the current scenario organizations should focus on key performance indicators (Ho, 2008).

Literature shows that business performance has been measured across various organizational settings. According to Zulkiffi and Perera (2011), directors, managers, and CEOs rate firm performance as a key factor when comparing themselves with the competitors.

\subsection{Entrepreneurial orientation and Organizational performance}

Scholarly work by Deshpande et al. (2013) denoted entrepreneurial orientation as the tendency and obligation of business through promising results in the business market, such as developing innovative ideas for new products and launching improved business operations to capture new markets, offering new 
products and services. Accordingly, the authors also suggest that organizations with entrepreneurial orientation encourage employees to feel independent in applying new ideas and strive to take risks. Besides this, entrepreneurial orientation has been conceptualized as a top management strategy, which involves risk-taking, innovativeness, and pro-activeness (Alam et al., 2015).

Besides this Boso et al. (2015) stated that entrepreneurial orientation can lead to improved business performance and can be a source of competitive advantage. Literature also shows a positive affiliation of entrepreneurial orientation with business or organizational performance (Lee et al., 2019). Similarly, other studies have also highlighted entrepreneurial orientation and its noteworthy effect on performance (Li et al., 2009). Importantly, the positive influence of entrepreneurial orientation was also found in studies based on SMEs in Iran (Jalali, Jaafar, \& Ramayah, 2014). Among SMEs in China, a significant association between entrepreneurial orientation and organizational performance was also witnessed (Zhang et al., 2012). Therefore, based on the literature, the current study proposed a significant positive relationship between entrepreneurial orientation and organizational performance. Hence, we hypothesized:

H1: Entrepreneurial orientation has a significant positive association with organizational performance

\subsection{Entrepreneurial orientation and organizational learning}

Prior research has shown the influence of entrepreneurial orientation (EO) on organizational learning (OL) in different aspects. According to the literature, entrepreneurial orientation can create a learningoriented atmosphere (Wang, 2008; Liu et al., 2002). These studies have shed light on the importance of EO as a helping tool for creating an environment and making firms capable of getting repeated successful learning prospects (Liu, Luo, \& Shi, 2002; Wang, 2008). Secondly, according to Lee and Sukoco (2007), learning can be affected by entrepreneurial orientation through a proper process. Thirdly, Hughes et al. (2007) stated that EO helps promote different activities related to learning. Through these activities, organizations can build a learning and knowledge acquisition based environment. Entrepreneurial orientation has shown a positive effect on strategic learnings and performance (Hughes, Hughes, \& Morgan, 2007).

Accordingly, entrepreneurial orientation has shown a direct relationship with knowledge creation process. Furthermore, entrepreneurial orientation and organizational performance relationship has also been proved through the mediation of knowledge creation ( $\mathrm{Li}$ et al., 2009). Through EO, information can be acquired, shared, and formatted, and all these factors are considered crucial for learning. In addition, the link between entrepreneurial orientation and learning in developing markets has also been examined (Hughes et al., 2007). Their study found theoretical consistencies of entrepreneurial orientation relationship in line with firm performance. Additionally, their argument supports the notion that EO will be important when associated with those firms whose workers are weak in learning. Based on these results from the existing literature, we proposed that entrepreneurial orientation will offer a huge contribution to organizational learning. Hence the present study hypothesized:

$\mathrm{H} 2$ : Entrepreneurial orientation has a significant positive association with organizational learning.

\subsection{Organizational learning and organizational performance}

According to Yeo (2007), organizations have to be learning-oriented. Goh et al. (2012) stated that organizational learning is an important aspect that helps businesses achieve competitive advantage. Literature shows that substantial consequence of organizational learning on organizational performance. Scholarly work by Matlay et al. (2006) on senior managers in India found a positive and significant association of organizational learning with business performance, which can be narrated as organizational performance (Matlay et al., 2006).

Though organizational learning has four key dimensions such as information delivery, information understanding, information access and organizational retention (Wang \& Ellinger, 2011). Besides this, Goh 
et al. (2007) and Wang (2008) have conceptualized organizational learning as both multi and unidirectional construct. Furthermore, Chakrabarty and Roge (2002) scholarly work worked on the dimensionality of organizational learning by using CFA approach through LISREL and recognized the uni-dimensionality for the construct. Uni-dimensionality was also assessed by (Goh et al., 2007). In view of this evidence, the current study has used organizational learning as a unidirectional construct (Chakrabarty \& Rogé, 2002). The reason behind using uni-dimensionality of organizational learning was also to reduce redundancy issues that often arise in constructs with multiple dimensions.

H3: Organizational learning will positively influence organizational performance

Literature shows that learning has played a vital mediating role between entrepreneurial orientation and performance(Wang, 2008). Hence, the current study research framework followed Barron and Kenny (1986) recommendation that a mediator should associate with independent variables and dependent variables such as $\mathrm{EO} \rightarrow \mathrm{OL}, \mathrm{OL} \rightarrow \mathrm{OP}$. Thus, organizational learning has both characteristics based on cited literature. Therefore, the current study used organizational learning as mediating variable among entrepreneurial orientation and organizational learning (Baron \& Kenny, 1986).

H.4: Organizational learning will mediate the relationship between entrepreneurial learning and organizational learning.

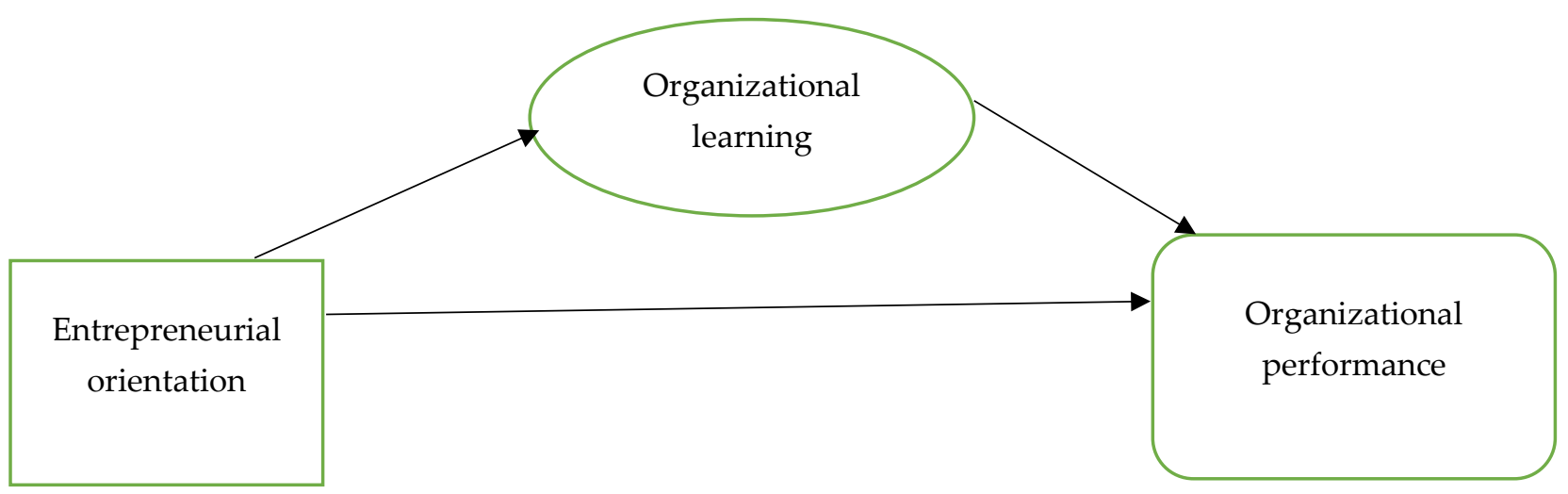

Figure 1. Conceptual Framework

\section{Methodology}

\subsection{Participants and Procedures}

The current study selected managers and owners from the Indonesian pharmaceutical SMEs as the unit of analysis. A total of 340 respondents were selected through purposive sampling (Sekaran \& Bougie, 2016), using the survey technique. The initial data screening was done using SPSS 23 for data screening to assess missing values, outliers, collinearity for robust data analysis. Further, after data screening through SPSS 23, the current study tested the model through PLS algorithm to check reliability and validity (Hair et al., 2016). In this, the bootstrapping approach was applied using 5000 subsamples to test the hypothesized relationships. Structural equation modeling is rigorously applied in several prominent studies, particularly in the management-related fields (AlZgool et al., 2020; Darwish et al., 2020; Ringle et al., 2020).

\subsection{Instruments}

Beside the demographic questions, the questionnaire contained 3 adapted items on entrepreneurial orientation from Miller (2011) and four items adapted regarding organizational learning from Kandemir 
and Hult (2005). Lastly, 5 item scale from Henri (2006) was adapted to test organizational performance (Henri, 2006).

\section{Data Analysis}

The current study applied the two-step approach as recommended by Hair et al. (2016). At first, the study examined the psychometric properties of the model, known as measurement model assessment. Upon confirming this, the study tested the significance of hypothesized relationships in the structural model stage.

\subsection{Measurement Model}

Table 2. Measurement Model

\begin{tabular}{lllll}
\hline Latent Variables & Loadings & CR & AVE & $\mathbf{R}^{2}$ \\
\hline EO & & & & \\
Innovativeness & 0.871 & 0.918 & 0.789 & \\
Risk taking & 0.899 & & & \\
Pro activeness & 0.893 & & & \\
OL & & & \\
OL1 & 0.695 & 0.863 & 0.613 & \\
OL2 & 0.825 & & & \\
OL3 & 0.837 & & & \\
OL4 & 0.768 & & \\
OP & & & \\
OP1 & 0.85 & 0.672 \\
OP2 & 0.82 & & \\
OP3 & 0.741 & & \\
OP4 & 0.773 & & \\
OP5 & 0.726 & & \\
\hline
\end{tabular}

Structural equation modeling was used as a technique to assess the model of the current study. At first stage measurement of model was assessed (Hair et al., 2016). In this, the current study model was assessed for reliability, validity (convergent and discriminant). All items loading factors were found well above the minimum criteria of 0.50 . As for as concern to reliability, the recommended score of reliability is 0.70 (Hair et al., 2011). Hence the current study achieved internal reliability for the model. Additionally, convergent validity through average variance extract was assessed. Based on the recommended benchmark of 0.50 value for AVE by (Chin, 1998), the current study found all AVE scored above 0.50 .

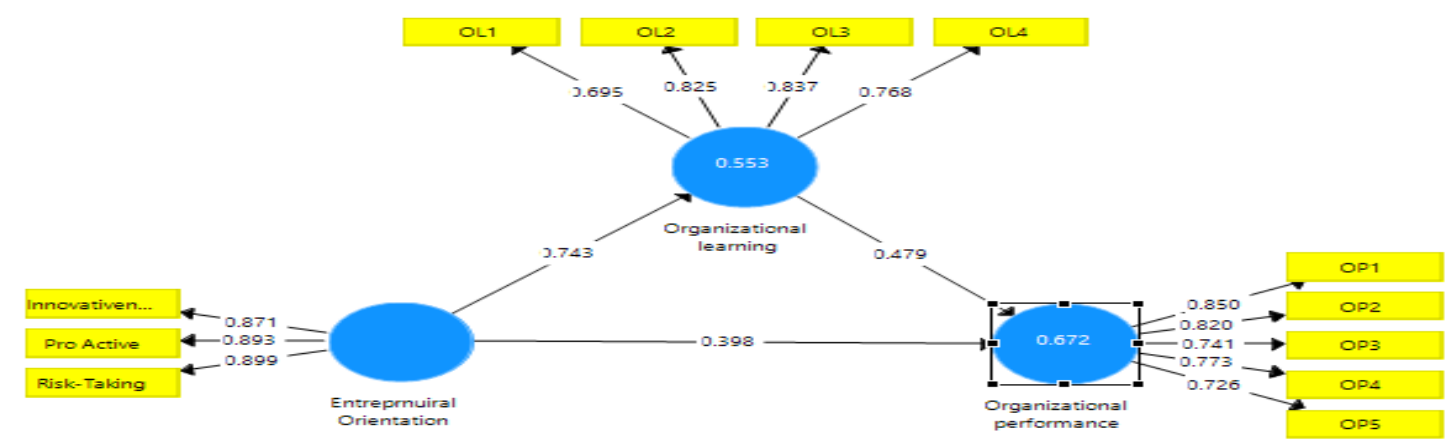

Figure 2. Measurement Model 
Table 3. HTMT (heterotrait-monotrait ratio of correlations)

\begin{tabular}{lccc}
\hline & 1 & 2 & 3 \\
\hline Entrepreneurial Orientation & ------ & & \\
Organizational learning & 0.885 & ----- & \\
Organizational performance & 0.872 & 0.843 & ----- \\
\hline
\end{tabular}

Beside the reliability and convergent validity, discriminant validity was also assessed through HTMT values. Minimum ranges of HTMT values must be less than HTMT0.85 and HTMT0.90. The current study found all HTMT values within the given range (Henseler, Ringle, \& Sarstedt, 2015).

\subsection{Structural Model Assessment}

After successfully measuring the model, the structural model was assessed through bootstrapping by applying structural equation modeling to know the significance of path co-efficient (Hair et al., 2014). Concern to direct relationship, current study found positive significant conclusion of entrepreneurial orientation on organizational performance $(\beta=0.398 ; t=7.098 ; \mathrm{p}<0.000)$ and with organizational learning $(\beta=0.743 ; \mathrm{t}=27.145 ; \mathrm{p}<0.000)$. Accordingly, the relationship between organizational learning and organizational performance was also found to be significant $(\beta=0.479 ; \mathrm{t}=8.117 ; \mathrm{p}<0.000)$. While the results for mediating hypothesis showed a significant positive effect. However, the indirect relationship beta decreased from 0.398 to 0.356 . Furthermore, the $t$ value increased in the indirect relationship from 7.098 to 7.75. Hence the study confirmed the mediation of organizational learning in the relationship between entrepreneurial orientation and organizational performance $(\beta=0.356 ; t=7.775 ; \mathrm{p}<0.000)$. Results are depicted in table 4 and figure 3.

Table 4. Hypothesis Results

\begin{tabular}{lllll}
\hline Hypothesis & Beta & t-value & p-value & Decision \\
\hline EO $->$ OL & 0.743 & 27.145 & 0000 & Supported \\
EO $->$ OP & 0.398 & 7.098 & 0000 & Supported \\
OL $->$ OP & 0.479 & 8.117 & 0000 & Supported \\
EO $\rightarrow$ OL $\rightarrow$ OP & 0.356 & 7.775 & 0000 & Supported \\
\hline
\end{tabular}

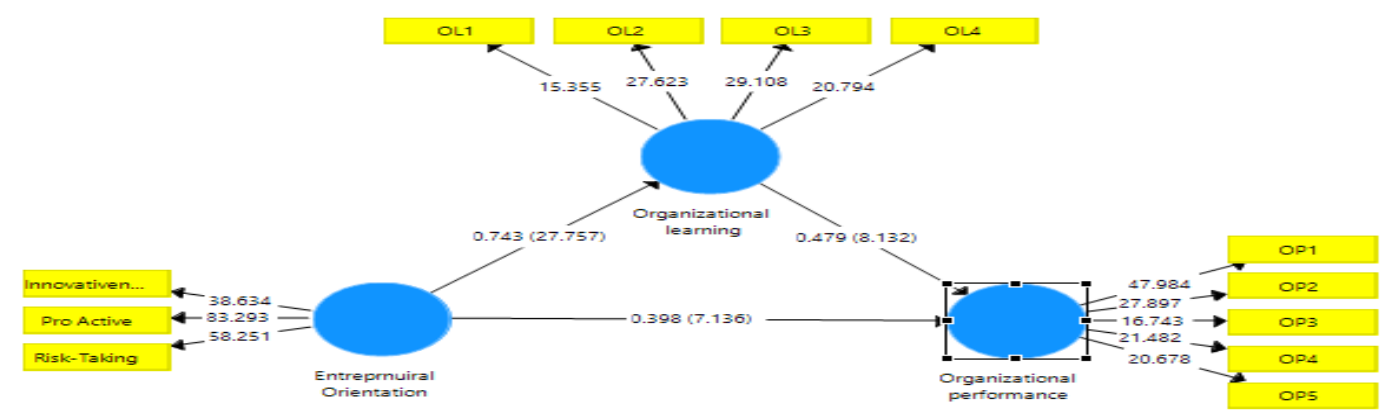

Figure 3. Structural Model

\section{Discussion}

The current study stressed the prominence of organizational performance by centering on entrepreneurial orientation, organizational learning of owners and or managers from SMEs in the pharmaceutical sector in Indonesia. The current study empirically proved that entrepreneurial orientation and organizational learning are healthy to enhance organizational performance. The study results land support to the existing literature both in entrepreneurial orientation to organizational performance 
association (Boso et al., 2015) and in entrepreneurial orientation towards organizational learning (Liu et al., 2002). Accordingly, the findings support the scholarly result on organizational learning and organizational performance relationship (Goh et al., 2012). The findings are valuable contributions to knowledge and literature on this association, asserting that entrepreneurial orientation and organizational learning are important for organizational performance. Additionally, the current study has shown significant results between EO and EL, EO and EP, EL for effective organizational performance. While testing the mediation of organizational learning, the current study found a significant mediating effect, suggesting that managers and owners (respondents) feel better association passing through entrepreneurial orientation and organizational learning towards organizational performance.

\subsection{Implications}

The current study has contributed in both theoretically as well as practically. The current study has theatrically contributed by using organizational learning as mediating factor among entrepreneurial orientation and organizational performance. From the practical, the current study implies pharmaceutical SMEs in Indonesia to appreciate the various benefits that entrepreneurial orientation and organizational learning can bring to help boost organizational performance. Thus, organizations (pharmaceutical SMEs firms) should enhance the use of organizational learning as a resource for better organizational performance.

\subsection{Limitations and Future Research Directions}

Besides valuable contributions, the current study also has some limitations. The study tested entrepreneurial orientation and organizational learning towards organizational performance. Future research may be directed to test this framework by adding more variables. Due to time and financial constraints the current study focused on the cross-sectional approach. Therefore, future studies may consider the longitudinal approach. Furthermore, the current study was based on survey method; hence future studies may consider a qualitative or mixed-method approach. Lastly, the current study only focused on the pharmaceutical SMEs in Indonesia, the results limit the generalizability of the findings. Future studies may therefore consider testing the framework in different occupational sectors and industries.

\section{Conclusion}

The current study has addressed the critical importance of entrepreneurial orientation, organizational learning towards organizational performance. The study has filled a major literature gap while contributing to the body of knowledge. Additionally, the study has contributed significantly to these variables across the major SMEs sector of the pharmaceutical industry in Indonesia, which advise managers and policymakers to make organizations more effective in terms of performance through entrepreneurial orientation and organizational learning.

\section{References}

Alam, S. S., Mohd, R., Kamaruddin, B. H., \& Nor, N. G. M. (2015). Personal values and entrepreneurial orientations in Malay entrepreneurs in Malaysia. International Journal of Commerce and Management. 25(4), 385-401.

AlZgool, M. R. H., Ahmed, U., Shah, S. A., AlMaamary, Q., \& AlMahmoud, N. (2020). Examining the interplay of hr initiatives, knowledge management, technological capabilities and product innovation. Journal of Security $\mathcal{E}$ Sustainability Issues, 10(2).

Baron, R. M., \& Kenny, D. A. (1986). The moderator-mediator variable distinction in social psychological research: Conceptual, strategic, and statistical considerations. Journal of Personality and Social Psychology, 51(6), 1173. 
Boso, N., Story, V. M., Cadogan, J. W., \& Ashie, E. (2015). Complementary effects of entrepreneurial orientation, market orientation and network ties on performance of entrepreneurial firms in a developing economy Ideas in marketing: Finding the New and Polishing the Old (pp. 268-268): Springer.

Chakrabarty, S., \& Rogé, J. N. (2002). An evaluation of the organizational learning survey. Psychological Reports, 91(3_suppl), 1255-1267.

Chin, W. W. (1998). The partial least squares approach to structural equation modeling. Modern Methods for Business Research, 295(2), 295-336.

Darwish, S. A. A. D., Ahmed, U. M. A. I. R., \& Pahi, M. H. (2020). Innovative work behavior during COVID-19 for medical representative in the pharmaceutical industry: Test of a moderation model in bahrain. International Journal of Pharmaceutical Research, 12(4), 1927-1934.

Deshpandé, R., Grinstein, A., Kim, S.-H., \& Ofek, E. (2013). Achievement motivation, strategic orientations and business performance in entrepreneurial firms. International Marketing Review.

Gavrea, C., Ilies, L., \& Stegerean, R. (2011). Determinants of organizational performance: The case of Romania. Management \& Marketing, 6(2).

Goh, S. C., Elliott, C., \& Quon, T. K. (2012). The relationship between learning capability and organizational performance. The learning organization.

Goh, S. C., Quon, T. K., \& Cousins, J. B. (2007). The organizational learning survey: a re-evaluation of unidimensionality. Psychological Reports, 101(3), 707-721.

Hair, J. F., Ringle, C. M., \& Sarstedt, M. (2011). PLS-SEM: Indeed a silver bullet. Journal of Marketing theory and Practice, 19(2), 139-152.

Hair Jr, J. F., Sarstedt, M., Hopkins, L., \& Kuppelwieser, V. G. (2014). Partial least squares structural equation modeling (PLS-SEM). European Business Review.

Hair Jr, J. F., Hult, G. T. M., Ringle, C., \& Sarstedt, M. (2016). A primer on partial least squares structural equation modeling (PLS-SEM). Sage publications.

Henri, J.-F. (2006). Organizational culture and performance measurement systems. Accounting, Organizations and Society, 31(1), 77-103.

Henseler, J., Ringle, C. M., \& Sarstedt, M. (2015). A new criterion for assessing discriminant validity in variance-based structural equation modeling. Journal of the Academy of Marketing Science, 43(1), 115-135.

Ho, L. A. (2008). What affects organizational performance? Industrial Management \& Data Systems.

Hughes, M., Hughes, P., \& Morgan, R. E. (2007). Exploitative learning and entrepreneurial orientation alignment in emerging young firms: Implications for market and response performance. British Journal of Management, 18(4), 359-375.

Jalali, A., Jaafar, M., \& Ramayah, T. (2014). Entrepreneurial orientation and performance: the interaction effect of customer capital. World Journal of Entrepreneurship, Management and Sustainable Development.

Kandemir, D., \& Hult, G. T. M. (2005). A conceptualization of an organizational learning culture in international joint ventures. Industrial Marketing Management, 34(5), 430-439.

Lee, C.-C., Lin, S.-P., Yang, S.-L., Tsou, M.-Y., \& Chang, K.-Y. (2013). Evaluating the influence of perceived organizational learning capability on user acceptance of information technology among operating room nurse staff. Acta Anaesthesiologica Taiwanica, 51(1), 22-27.

Lee, H., Ahmed, U., Zhussupova, B., \& Khalid, N. (2019). Impact of innovation capability and competitiveness on entrepreneurial orientation regarding to the entrepreneurial education in business performance among South Korean firms. Polish Journal of Management Studies, 20.

Lee, L., \& Sukoco, B. M. (2007). The effects of entrepreneurial orientation and knowledge management capability on organizational effectiveness in Taiwan: the moderating role of social capital. International Journal of Management, 24(3), 549.

Li, Y.-H., Huang, J.-W., \& Tsai, M.-T. (2009). Entrepreneurial orientation and firm performance: The role of knowledge creation process. Industrial Marketing Management, 38(4), 440-449.

Liu, S. S., Luo, X., \& Shi, Y.-Z. (2002). Integrating customer orientation, corporate entrepreneurship, and learning orientation in organizations-in-transition: an empirical study. International Journal of Research in Marketing, 19(4), 367-382.

Matlay, H., Khandekar, A., \& Sharma, A. (2006). Organizational learning and performance. Education+ Training. 48(8/9), 682-692. 
Mehralian, G., Nazari, J. A., Nooriparto, G., \& Rasekh, H. R. (2017). TQM and organizational performance using the balanced scorecard approach. International Journal of Productivity and Performance Management.

Miller, D. (2011). Miller (1983) revisited: A reflection on EO research and some suggestions for the future. Entrepreneurship theory and practice, 35(5), 873-894.

Ringle, C. M., Sarstedt, M., Mitchell, R., \& Gudergan, S. P. (2020). Partial least squares structural equation modeling in HRM research. The International Journal of Human Resource Management, 31(12), 1617-1643.

Rosli, R. M., Lokman, A. M., Aziz, A. A., \& Hamidi, S. R. (2015). Factors contributing to internet abuse in the workplace: Behaviour in SMEs. Paper presented at the Proceedings of the International Symposium on Research of Arts, Design and Humanities (ISRADH 2014).

Sekaran, U., \& Bougie, R. (2016). Research methods for business: A skill building approach: John Wiley \& Sons.

Siriattakul, P., Saengchai, S., \& Jermsittiparsert, K. (2019). The Mediating Role of Employee Engagement between Team and Co-worker Relation, Work Environment, Training and Development and Employee Performance. International Journal of Psychosocial Rehabilitation, 23(4).

Teeratansirikool, L., Siengthai, S., Badir, Y., \& Charoenngam, C. (2013). Competitive strategies and firm performance: the mediating role of performance measurement. International Journal of Productivity and Performance Management.

Wang, C. L. (2008). Entrepreneurial orientation, learning orientation, and firm performance. Entrepreneurship Theory and Practice, 32(4), 635-657.

Wang, Y.-L., \& Ellinger, A. D. (2011). Organizational learning: Perception of external environment and innovation performance. International Journal of Manpower, 32(5-6), 512-536.

Yeo, R. K. (2008). Identifying the competitive sword: learning to be cutting-edge for organizational development. Business Strategy Series.

Zhang, X., Ma, X., \& Wang, Y. (2012). Entrepreneurial orientation, social capital, and the internationalization of SMEs: Evidence from China. Thunderbird International Business Review, 54(2), 195-210.

Zulkiffli, S. N. A., \& Perera, N. (2011). A Literature Analysis on Business Performance For SMEs: Subjective or Objective Measures? Paper presented at the Society of Interdisciplinary Business Research (SIBR) 2011 Conference on Interdisciplinary Business Research.

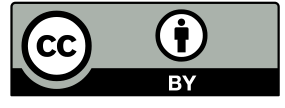

(c) 2021 by the author(s). Published by Annals of Contemporary Developments in Management \& HR (ACDMHR), under the terms and conditions of the Creative Commons Attribution (CC BY) license which can be accessed at http://creativecommons.org/licenses/by/4.0. 